\title{
The spinosyn family of insecticides: realizing the potential of natural products research
}

\author{
Herbert A Kirst
}

The spinosyns are a large family of unprecedented compounds produced from fermentation of two species of Saccharopolyspora. Their core structure is a polyketide-derived tetracyclic macrolide appended with two saccharides. They show potent insecticidal activities against many commercially significant species that cause extensive damage to crops and other plants. They also show activity against important external parasites of livestock, companion animals and humans. Spinosad is a defined combination of the two principal fermentation factors, spinosyns A and D. Structure-activity relationships (SARs) have been extensively studied, leading to development of a semisynthetic second-generation derivative, spinetoram. The spinosyns have a unique mechanism of action (MOA) involving disruption of nicotinic acetylcholine receptors. When compared with many other insecticides, the spinosyns generally show greater selectivity toward target insects and lesser activity against many beneficial predators as well as mammals and other aquatic and avian animals. Their insecticidal spectrum, unique MOA and lower environmental effect make them useful new agents for modern integrated pest management programs. As a result, this work has received U S Presidential Green Chemistry Challenge Awards.

The Journal of Antibiotics (2010) 63, 101-111; doi:10.1038/ja.2010.5; published online 12 February 2010

Keywords: ectoparasiticide; insecticide; natural product; spinetoram; spinosad; spinosyn

\section{INTRODUCTION}

Natural products have often been extolled as highly valuable and productive resources for uncovering a rich diversity of novel chemical structures, pharmaceutical or agrochemical leads and unique medicinal chemistry templates that show diverse biological activities. ${ }^{1-8}$ As such, natural products provide valuable alternatives for finding new directions in medicinal chemistry discovery programs that are not readily available through other chemical approaches, such as screening of large existing compound libraries, synthesis of newer analogs of known agents, creation of synthetic combinatorial chemistry libraries or applications of computer-guided synthesis. Although they possess their own set of significant challenges, natural products provide unique opportunities for exploring uncharted chemical spaces and opening new frontiers of structural novelty that are otherwise unattainable by other discovery strategies.

The spinosyns are a unique family of fermentation-derived insecticides having potent activity and lower environmental effect. The discovery and commercial development of these agents is an example of latter-day success for natural products in fulfilling its creative potential to find novel, commercially useful and valuable new products. This review will summarize the history of the spinosyns and provide an overview of their key features and their development into important commercial agents for insect treatment and control.

\section{DISCOVERY OF SPINOSYNS}

Isolation of microorganisms from diverse soil samples, fermentation of such soil-derived microbes under defined conditions and screening of the resultant fermentation broths or partially purified extracts is a long-honored methodology for finding new chemical structures showing desirable biological activities. ${ }^{1,9-12}$ Beginning with the discovery of penicillin, these methods generally reached their pinnacle in the 1950s and 1960s, at which time most antibiotic classes in therapeutic use today had been discovered. Subsequent years witnessed a slow but steady decrease in the discovery of important new fermentation products, but despite diminishing returns during that period, many large pharmaceutical companies had not yet eliminated their natural product programs.

The discovery of the avermectins and their potent anthelmintic and other anti-parasitic activities revolutionized the field of veterinary medicine by introducing a commercially successful product showing strong activity against both ectoparasites and endoparasites, which was thus termed an endectocide. ${ }^{13,14}$ Subsequent studies of the structurally similar milbemycins revealed similar activities. This important and highly successful family of drugs spurred strong interest in finding other novel molecules that would show similar or superior endectocidal properties.

One strategy for finding new fermentation products was to investigate non-traditional microorganisms (not Streptomyces or 
Micromonospora). During the course of such a program at Eli Lilly and Company in the early 1980s, a novel microbe was isolated from a soil sample collected at a rum still in the Virgin Islands. ${ }^{15}$ It was identified by taxonomic studies as a new species of a less common genus of soil actinomycetes and was named Saccharopolyspora spinosa sp. nov. and assigned the corporate code number A83543. ${ }^{15}$ A discovery screening program had also been established to search for new endectocides from fermentation. A critical component of that program was the development of a 96-well microtiter plate assay to look for inhibitors of mosquito larvae. This assay was sufficiently sensitive, selective and amenable to the higher capacity needed to efficiently screen a larger number of fermentation broths and extracts. When the A83543 culture broth was screened through this mosquito larvicide assay, insecticidal activity was recorded. The absence of antibacterial and antifungal activity suggested that this culture might possess selective activity rather than broad toxicity and thus might contain new compounds having a profile different from previously discovered ones. ${ }^{15-18}$

A long-recognized concern within fermentation products research has been the potential existence of an extremely potent new compound in the fermentation broth at only barely detectable amounts that could easily be overlooked and prematurely discarded. When analyzing any new fermentation broth, it is critical to account for all of the activity detected during screening to reasonably eliminate the chance that such an extremely potent molecule might be present to cause the observed activity. The spinosyns fit those concerns: extremely potent agents that were reproducibly active in the biological assays, but present in only minute amounts below the detectable level in HPLC analyses. These circumstances made isolation very difficult without a validated chromatographic assay containing an identified HPLC peak correlated with activity to guide separations. In spite of many substantial difficulties, the dedicated and logical persistence by the isolation chemists and fermentation microbiologists in maintaining the culture, following the activity and improving titers was eventually successful in locating the active components by HPLC. As a result, a novel family of structurally unique polyketides showing the sought-after insecticidal activity was finally obtained initially in very small amounts from the A83543 culture. ${ }^{15-22}$

\section{STRUCTURE AND SYNTHESIS}

The individual A83543 components were subsequently given the generic name of spinosyn to connect these compounds with their producing microorganism, S. spinosa. ${ }^{23}$ The major component in the fermentation is spinosyn A (1), whose structure is depicted in Figure $1 .{ }^{24}$ The structure was determined by NMR, MS and $\mathrm{X}$-ray analyses and comprises a tetracyclic polyketide aglycone to which is attached a neutral saccharide substituent (2,3,4-tri-O-methyl$\alpha$-L-rhamnosyl) on the C-9 hydroxyl group and an aminosugar moiety ( $\beta$-D-forosaminyl) on the C-17 hydroxyl group (Figure 1). The absolute configuration was established by the co-identity of forosamine, obtained by hydrolysis of spinosyn A, with D-forosamine obtained from hydrolysis of spiramycin. ${ }^{24}$ This spinosyn tetracyclic ring system composed of a cis-anti-trans-5,6,5-tricyclic moiety fused to a 12-membered lactone is a unique ring system. The most closely related structures seem to be the ikarugamycincapsimycin group, although they have a different substituent pattern and the opposite absolute stereochemistry of their 5,6,5 ring system, which is fused to a macrolactam containing an embedded tetramic acid. ${ }^{25,26}$

The second most abundant fermentation component is spinosyn D (2), which is 6-methyl-spinosyn A (Figure 1). Spinosyn D is likely formed by incorporation of propionate instead of acetate at the appropriate stage during polyketide assembly. ${ }^{16,27}$ Fermentation of S. spinosa produces a natural mixture containing spinosyn A as the major component and spinosyn $\mathrm{D}$ as the minor component, a mixture that has been named spinosad. ${ }^{23}$

This unique and highly complex core structure of the spinosyns has provided challenging opportunities for synthesis. The first synthesis yielded the enantiomeric (+)-A83543A because the absolute stereochemistry had not yet been established when this synthesis was begun. ${ }^{28}$ Total syntheses of the natural (-)-enantiomer have been subsequently accomplished. ${ }^{29,30}$ In addition, studies analyzing methodology for the synthesis of both the natural product and certain analogs have been conducted. ${ }^{31-34}$

\section{FERMENTATION-DERIVED ANALOGS}

Numerous structurally related compounds from various spinosyn fermentations have now been isolated and identified. Their structures fall into several general categories of single-type changes in the aglycone or saccharides of spinosyn A (Figure 2). ${ }^{16,17}$ Some factors have either one additional or one missing $C$-methyl group relative to spinosyn A, which would occur biosynthetically by interchanges of acetate and propionate at appropriate times during formation of the polyketide framework. In addition to spinosyn D (6-methyl-spinosyn A), other single $C$-methyl-modified factors include spinosyn $\mathrm{E}$ (16-demethyl-spinosyn A) and spinosyn F (22-demethyl-spinosyn A).

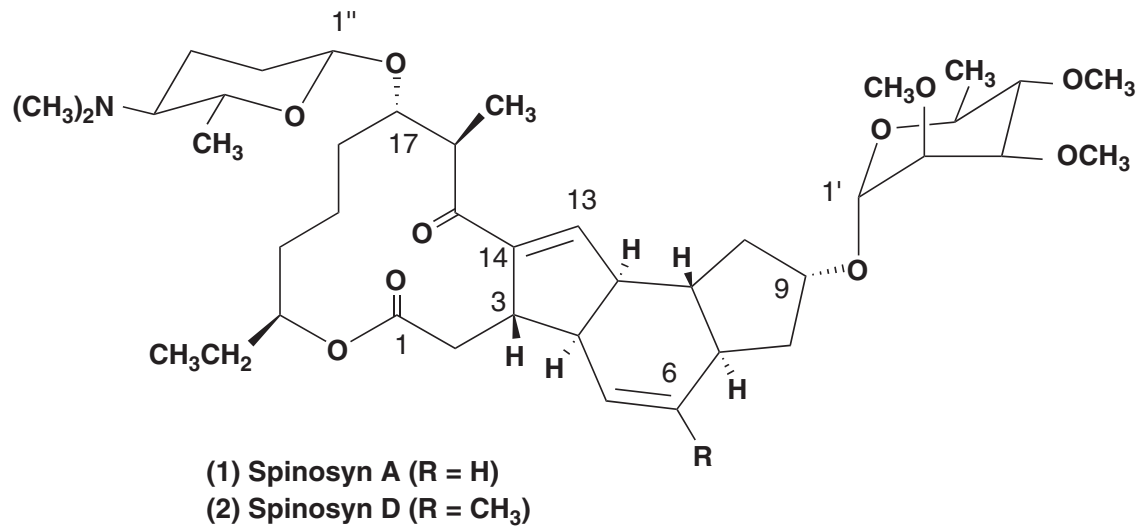

Figure 1 Structures of spinosyn A (1) and spinosyn D (2). 


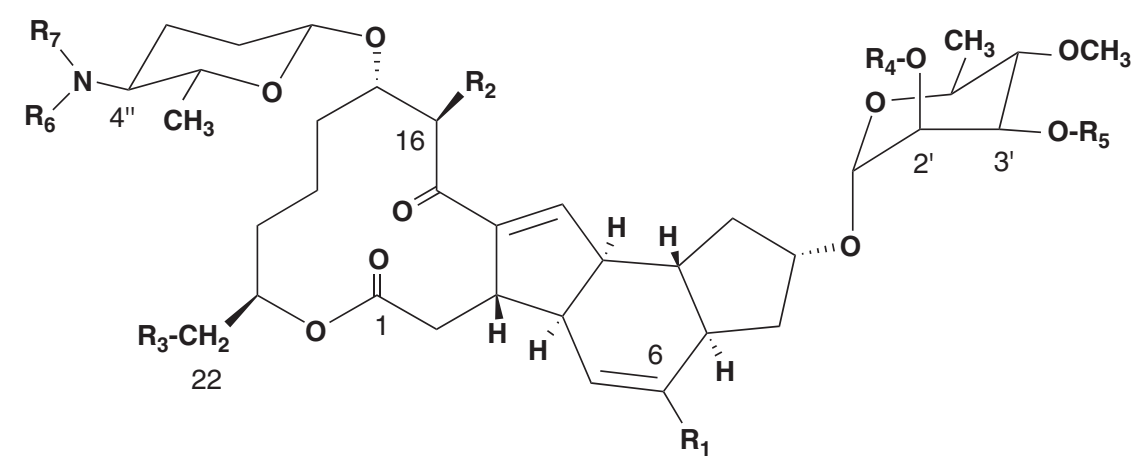

Figure 2 Variability in substituents found in initial spinosyn factors.

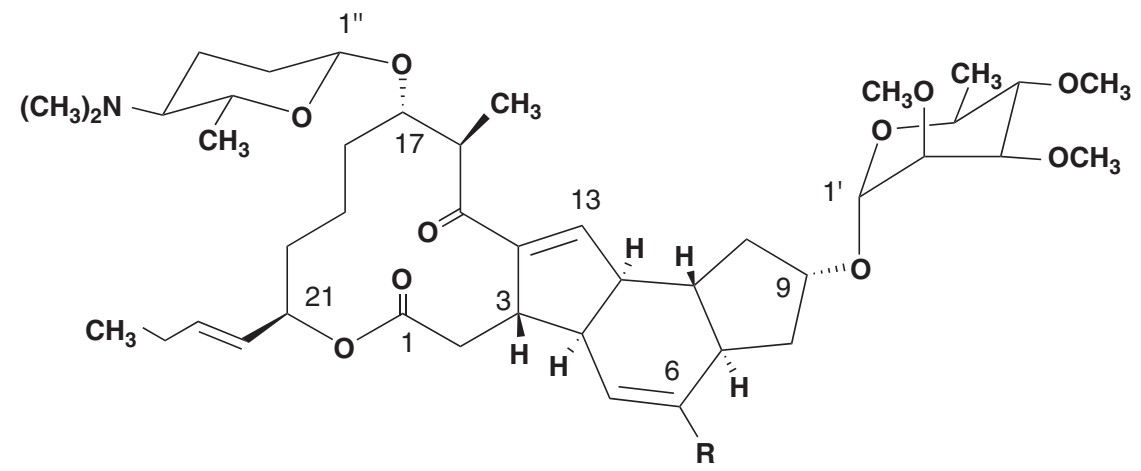

(3) Spinosyn $\alpha \mathbf{1}(\mathrm{R}=\mathrm{H})$

(4) Spinosyn $\delta 1\left(\mathrm{R}=\mathrm{CH}_{3}\right)$

Figure 3 Structures of representative 21-(2-Butenyl)-spinosyns.

Modifications of the two saccharides include spinosyn $\mathrm{H}\left(2^{\prime}-\mathrm{O}-\right.$ demethyl-spinosyn A), spinosyn $J$ (3'-O-demethyl-spinosyn A), spinosyn B (4"-N-demethyl-spinosyn A) and spinosyn C (4"'-di- $N$ demethyl-spinosyn A). Another structural change is replacement of the aminosugar, D-forosamine, by a different saccharide such as L-ossamine ( spinosyn G). ${ }^{16,35}$

One analog that was not found in the initially isolated series was 4'-O-demethyl-spinosyn A (spinosyn K). It was subsequently obtained from fermentation in the presence of the $O$-methyltransferase inhibitor, sinefungin, which proved to be a specific inhibitor of the $4^{\prime}-O$ methyltransferase in spinosyn biosynthesis. ${ }^{36}$ During the course of strain improvement studies, a variety of mutant strains of $S$. spinosa were isolated that had a non-functional $2^{\prime}-, 3^{\prime}$ - or $4^{\prime}$-O-methyltransferase. Fermentation studies of these biosynthetically blocked mutant strains alone or combined with the use of sinefungin yielded many additional factors having one or more changes in their patterns of $O$-, $\mathrm{N}$ - and/or $\mathrm{C}$-methyl substitution compared with spinosyn A; more than 20 such modified analogs of spinosyn A have now been isolated. ${ }^{18,36-38}$

More recently, another species of Saccharopolyspora, named $S$. pogona, was discovered that produces an even larger series of more than 30 structurally related compounds. ${ }^{39,40}$ One distinctive feature of many compounds in this newer series is a C-21-(2-butenyl) substituent in place of the previous 21-ethyl group, leading to the name of butenyl-spinosyns (or pogonins). 2-Butenyl analogs of spinosyns A (3) and D (4) are depicted in Figure 3. Some of the other components of this new series differ from the original spinosyn series with changes such as an $8 \beta$-hydroxyl group, a 17-O-sugar different from forosamine, a C-21 unsaturated substituent different from 2-butenyl or an expanded macrocyclic ring. ${ }^{39,40}$ The large number and wide diversity of known biosynthesized structures suggest that an even broader range of biosynthetic variations might be possible and that additional structural variations of the spinosyns may still yet be found. In addition, very little effort on bioconversions of the spinosyns has yet been reported. ${ }^{40}$

\section{BIOSYNTHESIS AND MOLECULAR MICROBIOLOGY}

The extremely low yields initially obtained from spinosyn fermentations prompted both strain improvement and fermentation development programs to increase titers. ${ }^{19,41,42}$ Fermentation development analyzed parameters such as oxygen consumption, antifoaming agents, media composition, nutrient requirements and growth conditions. ${ }^{19,42,43}$ One study found that spinosyn aglycone consumed all available deoxysugar, and hence duplication of genes stimulating deoxysugar biosynthesis was performed and spinosyn production was substantially increased. ${ }^{44}$ In addition to increasing titers, the strain development program created other mutant strains that were important for learning biosynthetic pathways. Initial studies showed that the aglycone of spinosyn A is assembled from nine acetate and two propionate units through a type I polyketide synthase (PKS) pathway and the two sugars are sequentially added to the aglycone, but many further details about the exact sequence and nature of these events were unknown or ambiguous. ${ }^{17,27,45}$ 
Cloning and analysis of the spinosyn biosynthetic gene cluster in S. spinosa provided a wealth of additional information. ${ }^{44,46,47}$ The anticipated PKS genes for assembling the polyketide chain were identified, but the specific mechanism(s) by which intramolecular crossbridging occurred to form the four rings of the aglycone was not definitively established. The proposed pathway involved thioesterase cleavage of the polyketide chain to form a 22-membered monocyclic macrolide whose subsequent intramolecular cyclizations were possibly controlled by the genes $s p n F, s p n J$, spnL or $s p n M .^{46-48}$ A subsequent investigation showed that SpnJ is an oxidase that converts the 15-hydroxyl group of the post-PKS monocyclized macrolactone (5) to a 15-keto group (6), but without any intramolecular cyclization (Figure 4). ${ }^{49}$ Elucidating the detailed nature of the intramolecular cyclization steps leading to the aglycone (7) remains the object of further analyses.

Analysis of the butenyl-spinosyn pathway showed analogous results with an additional PKS module to account for the C-21-butenyl group, suggesting a common origin for the two species. ${ }^{39}$ The C-21 substituent has also been altered by genetic engineering of the PKS starter module to accept a variety of non-natural substrates and then incorporate them into new unnatural C-21-modified spinosyn analogs..$^{50}$

A different genetically engineered mutant strain produced a new $17-\alpha$-O-L-olivosyl analog instead of the natural $\beta$-O-D-forosaminyl parent. ${ }^{51}$ Other recent studies have further characterized the enzymes involved in biosynthesis of the amino- and neutral sugars. ${ }^{52-55}$ The currently favored biosynthetic pathway for converting the aglycone (7) to spinosyn A (1) proceeds by addition of rhamnose, sequential $2^{\prime}-, 3^{\prime}$ and $4^{\prime}$-O-methylation and addition of forosamine (Figure 5). Further studies exploring the entire pathway of spinosyn biosynthesis and genetic engineering of various stages are likely to continue and to uncover intriguing results and novel applications.

\section{INSECTICIDAL ACTIVITY OF SPINOSAD}

Initial testing of the original series of spinosyns revealed potent and broad-spectrum activity from several factors against numerous commercially important insect pests. The spectrum of target insects included many species of Lepidoptera and Diptera along with some members of several other insect orders, such as planthoppers, leafhoppers, spider mites and cockroaches. ${ }^{20,23,36}$ The potent and broad activity showed against many problematic larval species of Lepidoptera was especially intriguing. Several publications and patents have subsequently reported extensive insecticidal data generated from the many natural spinosyns in detailed tabular formats. ${ }^{20,37,38,56,57}$ Spinosyn A was generally the most active factor, whereas spinosyn D was usually close to equipotent. Insecticidal activity against many problem species was often comparable to that of commercially used insecticides, including some pyrethroids. Insecticidal activity was observed after administration of the spinosyns by a variety of delivery methods, including contact and oral feeding assays.

The activities showed by the two primary naturally occurring factors, spinosyns A and D, were relatively similar, and hence the fermentation-derived mixture of spinosyn A (major component) and spinosyn D (minor component) was developed under the generic name of spinosad. ${ }^{23,58}$ Several commercial products containing spinosad as their active ingredient have now been produced by Dow AgroSciences (Indianapolis, IN, USA) as components of their Naturalyte series of insect control agents. ${ }^{59}$ These products include Tracer for the control of major worm pests on many field crops, SpinTor and Success for broad-spectrum insect control on a wide variety of crops, Conserve for insect control on turf and ornamental plants, Entrust for
9 Acetate and 2 Propionate

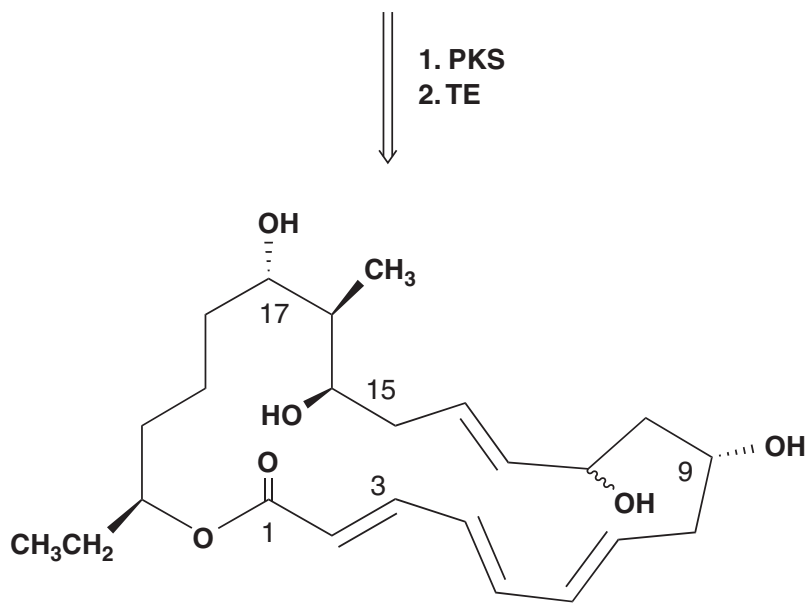

(5)<smiles>C=CSc1ccccc1</smiles>

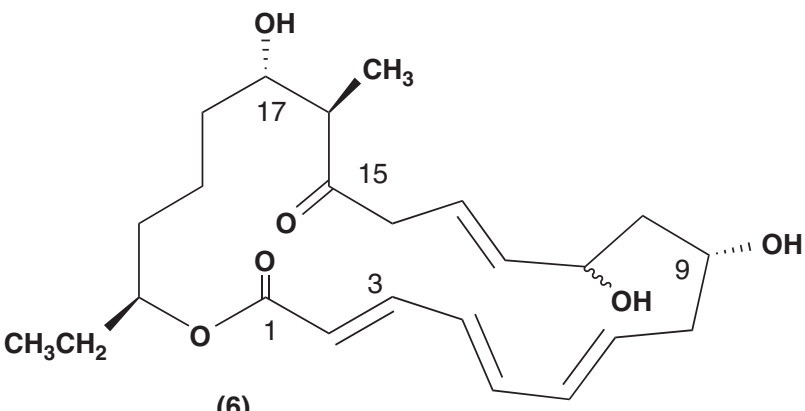

(6)<smiles>c1ccccc1</smiles><smiles>CC[C@H]1CCC[C@@H](O)[C@@H](C)C(=O)C2=CC3C(C=CC4C[C@@H](O)C[C@H]43)[C@H]2CC1=O</smiles>

(7) Spinosyn A Aglycone

Figure 4 Proposed post-PKS biosynthetic steps.

insect control on organic crops, and fruitfly and fire ant bait traps. ${ }^{59,60}$ The products are also useful in integrated pest management and insecticide resistance management programs. ${ }^{59}$ Furthermore, spinosad-containing products have been approved by several organizations in the United States and other countries for use in organic agriculture. ${ }^{60}$ The successful development of this efficacious new series of spinosad-based insect control pesticides having a reduced risk to nontarget species and lower potential for environmental damage when compared with other insecticides was awarded the Presidential Green Chemistry Challenge Award in 1999.60,61 


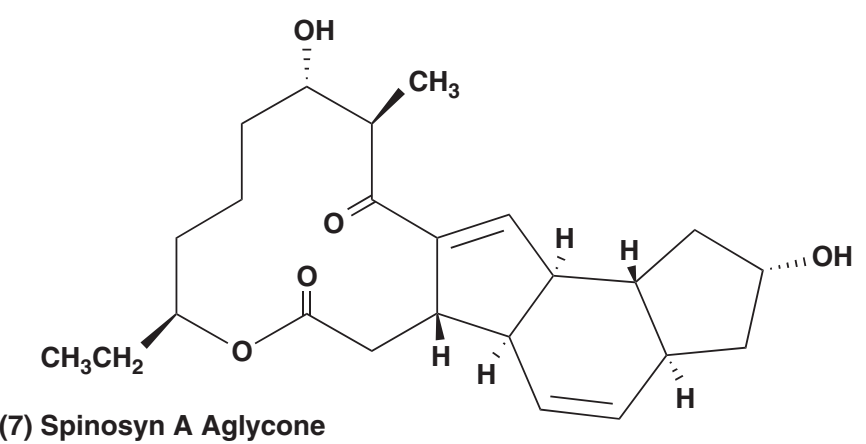

(7) Spinosyn A Aglycone

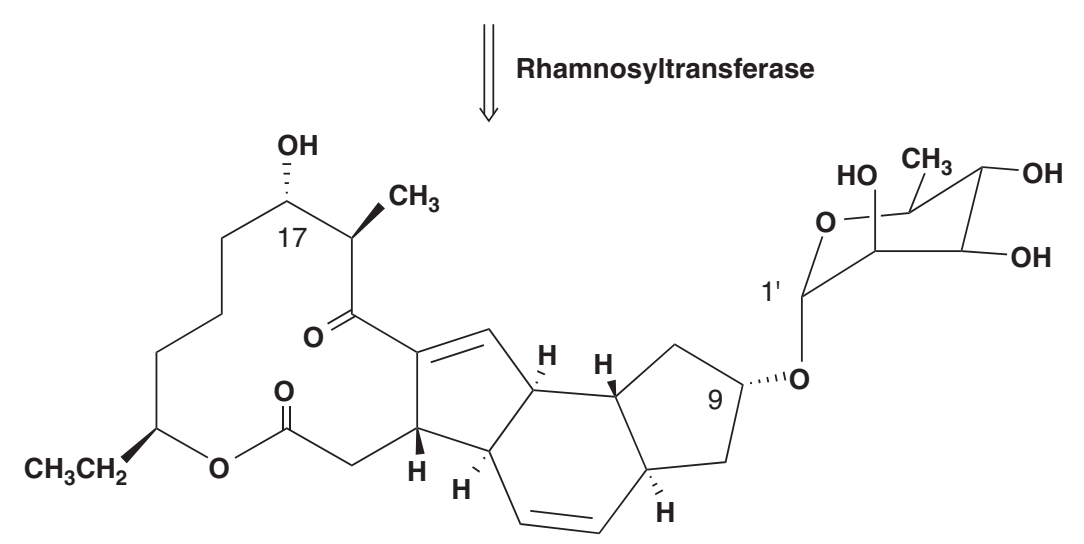

(8) 9-0-Rhamnosyl-Spinosyn A Aglycone

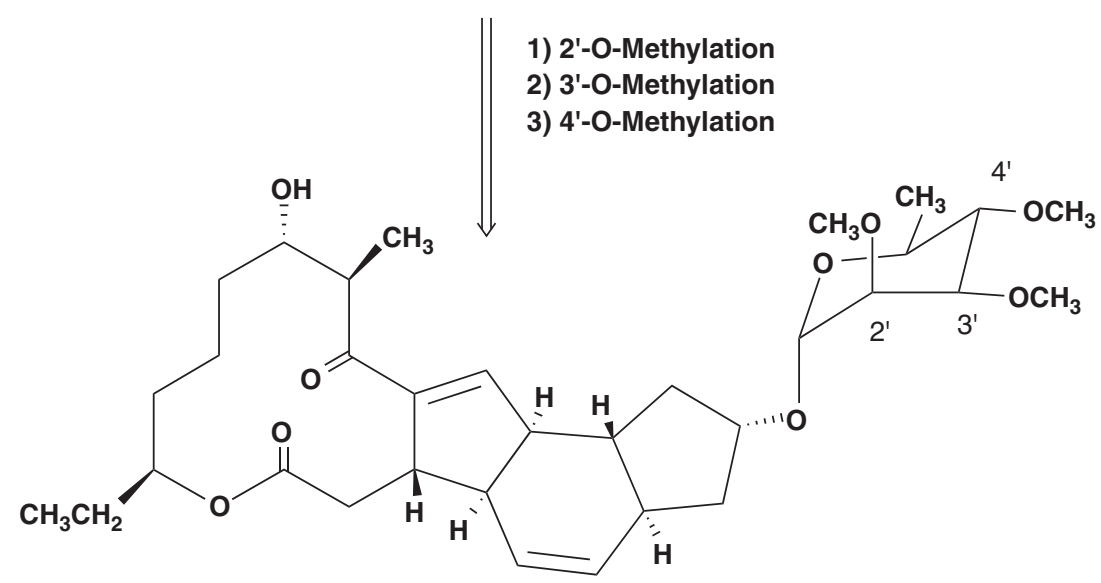

(9) 17-Pseudoaglycone

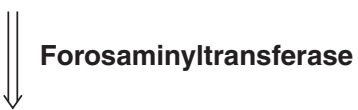

(1) Spinosyn A

Figure 5 Addition of saccharides to the spinosyn aglycone.

\section{VETERINARY AND HUMAN HEALTH ACTIVITIES}

Numerous insects and acarids, especially those that feed on a blood meal, cause many serious health problems and suffering for livestock, companion animals and humans. Consequently, as a result of their strong anti-parasitic activity, the spinosyns have been investigated since their discovery for potential veterinary applications. ${ }^{20,57}$ Using spinosad as the active ingredient, Elanco Animal Health (Greenfield,
IN, USA) has developed several applications for livestock animals. Extinosad was first registered in Australia in 2001 and then in New Zealand for control of blowfly strike, lice and maggots on sheep using several different delivery formats. ${ }^{57,62}$ It has also been developed in Australia as Elector PSP to control flies and darkling beetles on agricultural animal premises. ${ }^{62}$ More recently, with spinosad as its active ingredient, Elector was approved in the United States for control 
of hornflies and both sucking and chewing lice on cattle, and Elector PSP was approved for control of beetles and flies on agricultural animal premises. ${ }^{62-64}$

Ticks are another major blood-feeding parasite for which novel acaricides are needed. Spinosad has shown activity against several tick species in laboratory assays and has been analyzed for potential efficacy against Boophilus ticks on cattle. ${ }^{65-67}$ Other studies have been conducted to evaluate the potential utility of spinosad against several other problem insect parasites, such as screwworm and tsetse flies. ${ }^{68,69}$

Biting and blood-feeding parasites also cause serious problems of health and discomfort for companion animals as well as livestock. Several recent studies of spinosad have shown its efficacy against fleas when administered orally to dogs. ${ }^{70-72}$ Elanco Companion Animal Health has received US Food and Drug Administration approval for a chewable tablet named Comfortis that provides treatment and control of fleas on dogs with month-long protection. ${ }^{62}$ Preliminary studies are also being conducted for the potential efficacy of spinosad when administered orally against ticks in dogs. ${ }^{73}$

Another parasitic health problem is head lice afflicting humans. Spinosad has shown activity in laboratory bioassays against permethrin-susceptible body lice and permethrin-resistant head lice. ${ }^{74} \mathrm{~A}$ creme rinse product named Natrova containing spinosad as the active ingredient is currently under development by ParaPRO LLC (Carmel, IN, USA) for the treatment of head lice. ${ }^{75}$

\section{SEMISYNTHETIC DERIVATIVES AND SAR}

After their initial discovery and promising biological evaluations, the structural novelty and potent insecticidal activities of the spinosyns prompted a long-range program of preparation and testing of semisynthetic derivatives. From these extensive efforts, over 1000 analogs and derivatives have now been obtained and tested. ${ }^{18}$ Numerous publications have reported the preparation of a wide structural diversity of semisynthetic compounds, the evaluation of their biological activities and their structure-activity relationships (SARs). ${ }^{18,57,76-83}$ As space is limited, only a few results of the SAR will be summarized in this review.

It was recognized early that both saccharides are important for insecticidal activity. Forosamine was easily and selectively hydrolyzed from spinosyns under mildly acidic conditions, whereas selective removal of the neutral sugar was achieved from the biosynthetically blocked mutant-derived spinosyns J and L ( $3^{\prime}$-O-demethyl analogs of $\mathrm{A}$ and $\mathrm{D}$, respectively) through sequential $3^{\prime}$-oxidation and basecatalyzed elimination reactions (Figure 6) ${ }^{84,85}$ The diverse pseudoaglycone and aglycone derivatives were also useful in biosynthetic feeding studies to elucidate the plausibility and sequence of various post-PKS transformations. ${ }^{81}$ Initial SAR results indicated that forosamine could be replaced by certain nitrogen-containing sugar and non-sugar substituents with retention of some degree of activity. ${ }^{57}$ Similarly, activity was only retained after some limited changes in the structure of the neutral sugar, especially certain modifications at C-2' and $\mathrm{C}-3^{\prime}$ of the tri-O-methylrhamnose moiety. ${ }^{82,86}$

Early modifications of the tetracyclic core included several stereoselective reductions and epoxidations of the 5,6- and 13,14-double bonds (see Figure 1). ${ }^{57,87}$ However, the 6-methyl group of spinosyn D (2, Figure 1) substantially hindered hydrogenation of its 5,6-double bond. The biological activity of these oxidation and reduction products was usually dependent on the stereochemistry of the reaction products. In contrast, many of the other sites within the spinosyn aglycone had been inert to chemical modification because of their saturated hydrocarbon nature. The discovery of the butenyl-spinosyn series allowed access to several previously unachievable modifications by introducing several new chemical handles, including the C-21 unsaturated substituents, ring-expanded 14-membered lactone and C-8 hydroxyl group. Some modifications exploring the chemistry of some of these new butenyl-spinosyns have been recently reported. ${ }^{88}$

In addition to intensive examination and analysis of the emerging SAR trends by traditional medicinal chemistry methods, a neural network-based quantitative SAR study was also applied to the database of existing compounds and their activities. ${ }^{89-91}$ This application of artificial intelligence was used to help identify promising directions for further modifications of the spinosyn structure. Analysis of this artificial intelligence model suggested that $O$-alkyl groups on rhamnose that were longer than methyl would confer greater activity against tobacco budworm larvae and that lengthening the 3'-O-methyl group in particular would be the most beneficial approach to study. ${ }^{89}$ Thus, $3^{\prime}$-O-alkyl derivatives were synthesized using the fermentationderived mixture of spinosyns $J$ (11) and L (12) as starting material (Figure 7). In addition, previous studies of the 5,6-dihydro derivative of spinosyn A had shown some potentially advantageous improvements in spectrum, potency and photostability. ${ }^{91,92}$ Combining the reactions of $3^{\prime}$-O-ethylation and 5,6-reduction yielded the mixture of 3'-O-ethyl-5,6-dihydro-spinosyn $\mathrm{J}(\mathbf{1 4})$ and 3 '-O-ethyl-spinosyn $\mathrm{L}$ (15) that was named spinetoram (13) (Figure 7). It showed greater potency, earlier onset of activity and longer duration of control against certain insects when compared with spinosad while retaining broadspectrum insect control and low environmental effect on non-target species. ${ }^{91,92}$ In recognition of the innovative research approach that was used to improve upon the naturally occurring spinosyns while maintaining the reduced risk to non-target species and the lower potential for environmental damage compared with other insecticides, spinetoram was awarded the Presidential Green Chemistry Challenge Award for Designing Greener Chemicals by the US Environmental Protection Agency in 2008. ${ }^{91}$ Spinetoram has been successfully developed as the new commercial products Delegate and Radiant for insect control on a variety of agricultural crops. ${ }^{59}$

\section{MOA AND RESISTANCE}

Studies to date have concluded that the mechanism(s) by which spinosyn exerts its insecticidal action is different from those of any other known agents, and thus spinosyn has a unique, although as yet incompletely defined, mechanism of action (MOA). ${ }^{18,93}$ This conclusion is based upon the lack of an effect by spinosyn, either positive or negative, on binding of other known insecticides to their particular receptors. ${ }^{93}$ Initial investigations had concluded that the primary action of spinosyn A affected the insect nervous system and disrupted neuronal activity by exciting motor neurons and causing involuntary muscle contractions, eventually leading to paralysis and death. ${ }^{94,95}$ Later studies found that spinosyn interacted with both $\gamma$-aminobutyric acid receptors and nicotinic acetylcholine receptors, thereby implicating these receptors in the MOA, although in a manner distinct from the interactions by other insecticides. ${ }^{96}$ Subsequent investigations provided additional evidence for such a unique MOA, involving an unidentified subtype of nicotinic acid receptors as well as an antagonistic effect on $\gamma$-aminobutyric acid receptors. ${ }^{18,93,97}$ Most recently, knockout studies in Drosophila melanogaster implicated the $D \alpha 6$ subunit of the nicotinic acetylcholine receptor as a target site of spinosyn. ${ }^{98-100}$ Additional work will undoubtedly lead to the fuller delineation of the entire detailed MOA of these unique insecticides.

As one would expect for a new insecticide having a MOA different from those of other agents, cross-resistance between spinosyn and other agents was initially absent or low. ${ }^{18,101,102}$ This result reinforces the proposal for a unique MOA. However, as well known for other 


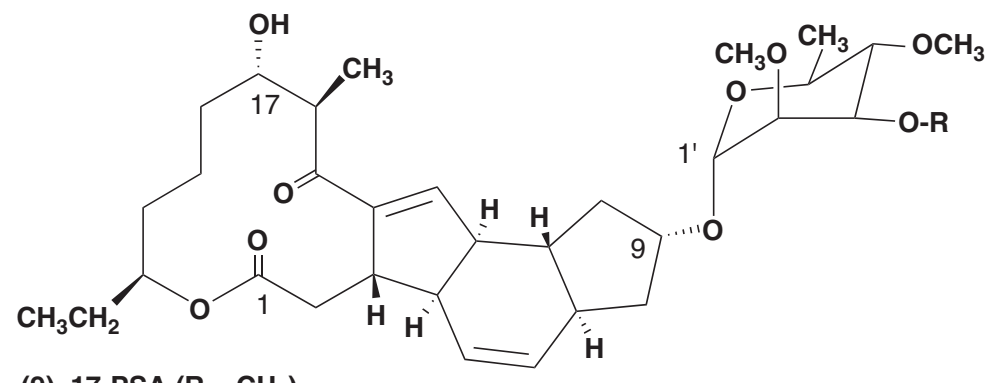

(9) 17-PSA (R= $\left.\mathrm{CH}_{3}\right)$

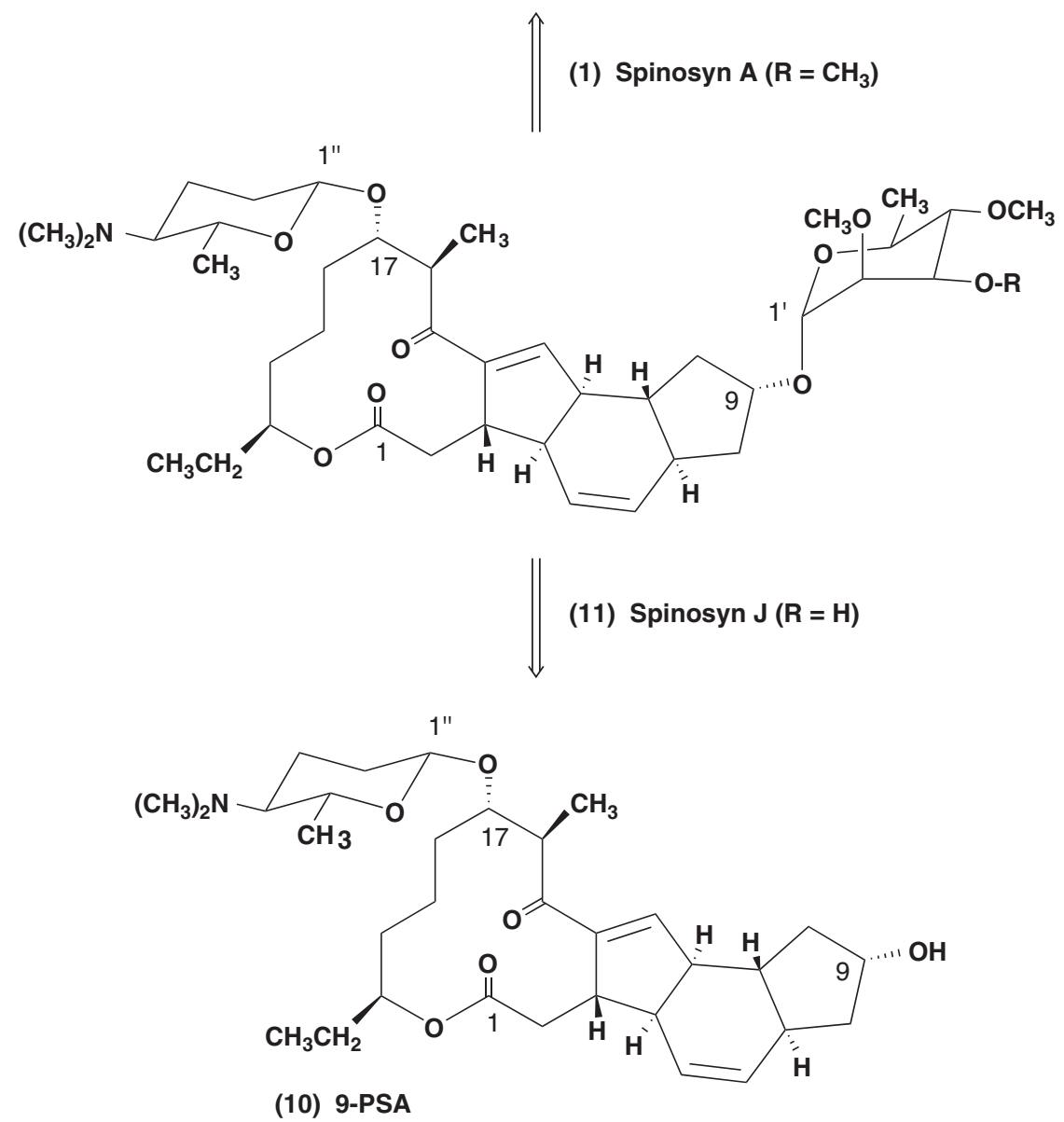

Figure 6 Structures of 9- and 17-pseudoaglycones of spinosyn A.

insecticides, continued usage is likely to exert selective pressures on insects and to eventually provoke resistance. Consequently, strategies and management practices to minimize and manage the potential development and spread of resistance are always critical to anticipate and plan early. ${ }^{18,58}$

A review of all reports of susceptibility and resistance is beyond the scope of this review. Generalized conclusions are difficult to make because published results are usually individual cases that have many different variables, such as the insect species and its development stage, type of treated plants, location and climate, management practices, type of assay, environmental effects, etc. One of the first cases of resistance development was reported in diamondback moths in Hawaii, although changes in management practices restored susceptibility, suggesting resistance was reversible. ${ }^{18,103,104}$ Among examples from various studies, resistance in codling moth larvae has varied from none to problematic. ${ }^{105,106}$ Resistance was reported in four of five field populations of beet armyworm in Mexico. ${ }^{107}$ A recent study reported that spotted bollworm on cotton in Pakistan remained generally susceptible. ${ }^{108}$ Variable degrees of cross-resistance in a variety of pest species between spinosad and some, but not all, other agents have been reported. ${ }^{109-114}$ Despite the many differences in details, the overriding conclusion of most studies is that rotation of different mechanistic classes of insecticides is critical to manage resistance problems. Combinations of insecticides have also been considered as means to minimize resistance. ${ }^{115}$

\section{ENVIRONMENTAL EFFECTS}

A major advantage of spinosad when compared with many other insecticides is its relatively selective activity against target insects, such as Lepidoptera and Diptera species, coupled with generally lesser 


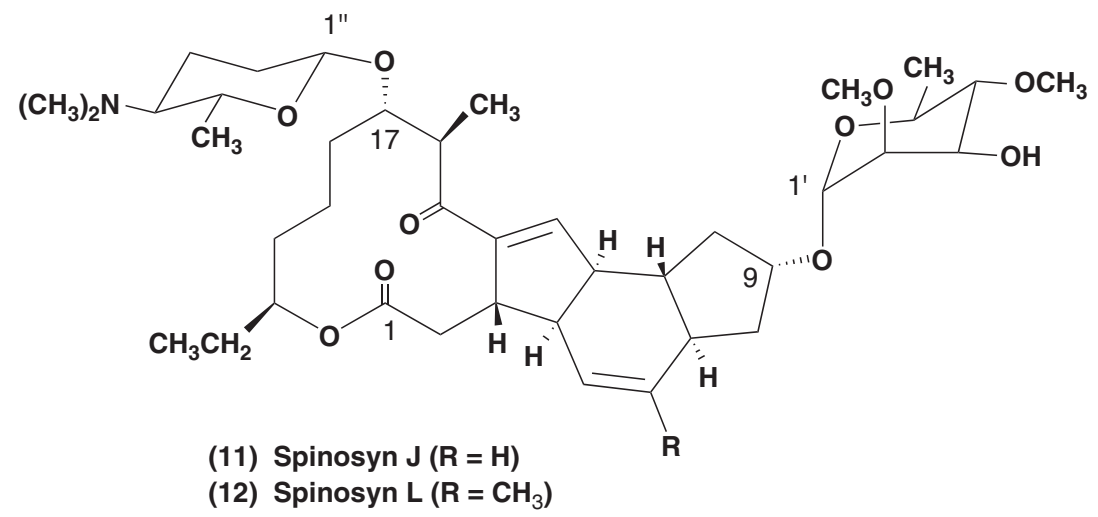

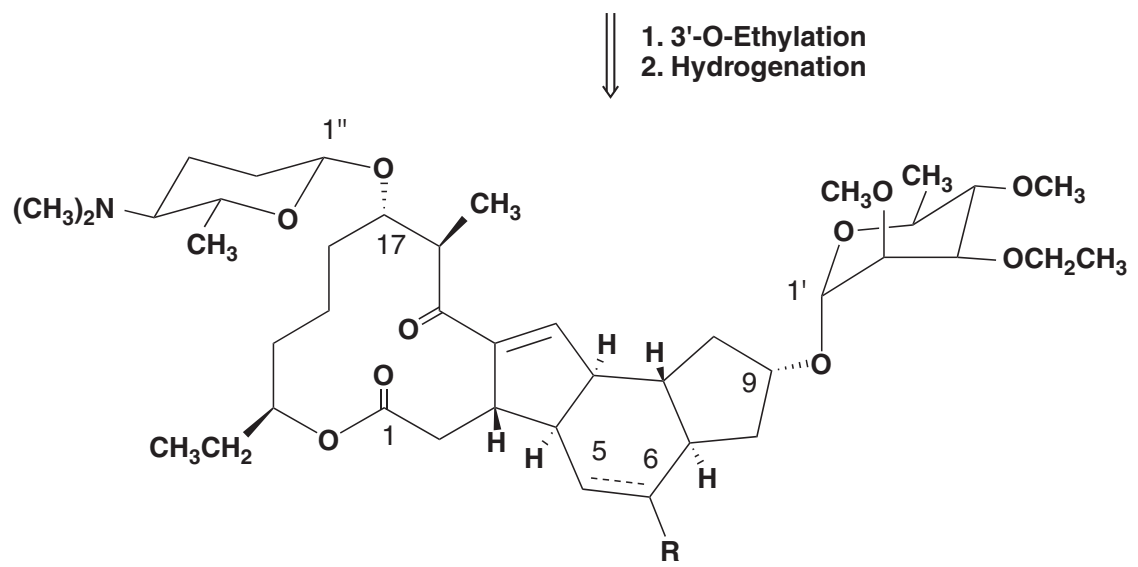

(13) Spinetoram: A Mixture of

(14) 3'-O-Ethyl-5,6-Dihydro-Spinosyn $\mathrm{J}(\mathrm{R}=\mathrm{H}$ and 5,6-single bond) and

(15) 3'-O-Ethyl-Spinosyn $\mathrm{L}\left(\mathrm{R}=\mathrm{CH}_{3}\right.$ and 5,6-double bond)

Figure 7 Origin and structure of spinetoram (13).

activity against many beneficial insect predators and other non-target species. ${ }^{18,37,58}$ Extensive studies of the effects of spinosad on many beneficial species have been published. ${ }^{116-123}$ Detailed results may vary depending on the specific species and their stage of development, the particular methods of administration and the type and timing of exposure to a species. ${ }^{122,123}$ Thus, critical factors such as timing and method of insecticide application that account for the potential presence of particular beneficial organisms can significantly diminish undesired effects on non-target species. The overall assessment is that the selectivity of the spinosyns against target species is significantly improved over many older insecticides and that spinosad has a reduced risk to beneficial species when compared with many other insecticides. ${ }^{18,116-126}$

Another important attribute of the spinosyns is their lower toxicity and reduced risk toward mammals and many other aquatic and avian animals when compared with many other insecticides. ${ }^{18,37,58,80}$ As it also occurs for insect predators, the detailed toxicology results vary, depending on the particular animal, route of administration, duration of exposure and other experimental variables. In addition, chronic studies showed that spinosad was not carcinogenic, mutagenic or teratogenic to mammals. ${ }^{58}$ Overall, spinosad has shown a significantly favorable improvement in its safety profile and therapeutic indices for mammals and other animals when compared with many other insecticides. $^{18,126}$
Several studies have found that spinosyn does not have a relatively long period of persistence in many parts of the environment. ${ }^{18,126}$ Facile sunlight-based photolytic processes are a major route of aqueous degradation along with partitioning into organic matter and sediments with subsequent biotic degradation in the absence of light. ${ }^{127,128}$ Spinosyns also did not show a lengthy persistence in soil and litter, presumably in large part due to facile degradation by soil organisms. ${ }^{128-131}$ Spinosyns have also been found to undergo facile metabolism in several mammals and fowl. ${ }^{18,132}$ Overall, the spinosyns are readily subject to a number of diverse degradative pathways and metabolic mechanisms that reduce their persistence in plants, animals and the environment.

\section{CONCLUSION}

Over 25 years have passed since research was initially begun on the spinosyns. During that period, many novel and unique results have been discovered from the research, development and commercialization of these remarkable natural products. Owing to numerous dedicated and persistent efforts from countless individuals, the spinosyns overcame many significant difficulties and obstacles in their discovery and development. As a result, they became a recent successful realization of the potential of natural products research for making truly new and important discoveries that would not have been achieved from other discovery programs. Such novel and 
valuable accomplishments can thereby justify the future time and resources that will be needed to further investigate natural products for their ability to provide different approaches and directions to discovering useful new products.

Just as previously demonstrated in Drosophila, the nicotinic acetylcholine receptor $\alpha 6$ is involved in the MOA of spinosyn against diamondback moths. ${ }^{133}$ A study of cross-resistance with spinosyn in tobacco budworm has been recently published. ${ }^{134}$ Efficacy of spinosad against cat fleas on dogs was also reported. ${ }^{135}$

\section{CONFLICT OF INTEREST}

Dr Herbert A Kirst is a retired chemist from Eli Lilly and Company where he conducted research on natural products, antimicrobial compounds and animal health agents, including spinosyn. He is currently an independent consultant for chemistry of natural products and anti-infective agents.

\section{ACKNOWLEDGEMENTS}

I thank Drs Tom Sparks and Jim Dripps of Dow Agrosciences and Dr Dan Snyder of Elanco Animal Health for their critical reviews of this paper and Dr Ray Yao (Lilly retiree) for historical information.

1 Demain, A. L. \& Sanchez, S. Microbial drug discovery: 80 years of progress J. Antibiot. 62, 5-16 (2009).

2 Dayan, F. E., Cantrell, C. L. \& Duke, S. O. Natural products in crop protection. Bioorg. Med. Chem. 17, 4022-4034 (2009).

3 Rosen, J., Gottfries, J., Muresan, S., Backlund, A. \& Oprea, T. I. Novel chemical space exploration via natural products. J. Med. Chem. 52, 1953-1962 (2009).

4 Osada, H. \& Hertweck, C. Exploring the chemical space of microbial natural products. Curr. Opin. Chem. Biol. 13, 133-134 (2009).

5 Cordier, C., Morton, D., Murrison, S., Nelson, A. \& O'Leary-Steele, C. Natural products as an inspiration in the diversity-oriented synthesis of bioactive compound libraries. Nat. Prod. Rep. 25, 719-737 (2008).

6 Grabowski, K., Baringhaus, K.- H. \& Schneider, G. Scaffold diversity of natural products: inspiration for combinatorial library design. Nat. Prod. Rep. 25, 892-904 (2008).

7 Newman, D. J. Natural products as leads to potential drugs: an old process or the new hope for drug discovery? J. Med. Chem. 51, 2589-2599 (2008).

8 Baker, D. D., Chu, M., Oza, U. \& Rajgarhia, V. The value of natural products to future pharmaceutical discovery. Nat. Prod. Rep. 24, 1225-1244 (2007).

9 Baltz, R. H. Antibiotic discovery from actinomycetes: will a renaissance follow the decline and fall? SIM News 55, 186-196 (2005).

10 Harvey, A. L. Natural products as a screening resource. Curr. Opin. Chem. Biol. 11, 480-484 (2007).

11 Von Nussbaum, F., Brands, M., Hinzen, B., Weigand, S. \& Habich, D. Antibacterial natural products in medicinal chemistry - exodus or revival? Angew. Chem. Int. Ed. 45, 5072-5129 (2006)

12 Pelaez, F. The historical delivery of antibiotics from microbial natural products-can history repeat? Biochem. Pharmacol. 71, 981-990 (2006)

13 Campbell, W. C. (ed). Ivermectin and Abamectin (Springer, New York, 1989).

14 Kornis, G. I. Avermectins and milbemycins. in Agrochemicals from Natural Products (ed Godfrey, C.R.A.) 215-255 (Marcel Dekker, New York, 1995).

15 Mertz, F. P. \& Yao, R. C. Saccharopolyspora spinosa sp. nov. isolated from soil collected in a sugar mill rum still. Int. J. System. Bacteriol. 40, 34-39 (1990).

16 Kirst, H. A. et al. Discovery, isolation, and structure elucidation of a family of structurally unique, fermentation-derived tetracyclic macrolides. in Synthesis and Chemistry of Agrochemicals III (eds Baker, D. R., Fenyes, J. \& Steffens, J. J.) 214-225 (American Chemical Society, Washington DC, 1992)

17 Kirst, H. A. et al. Discovery and identification of a novel fermentation-derived insecticide. in Developments Indust. Microbiol. Vol. 32, 1st edn Microbial Metabolites (eds Nash, C., Hunter-Cevera, J., Cooper, R., Eveleigh, D. E. \& Hamill, R.) 109-116 (Brown Publishers, Dubuque, IA, 1993).

18 Salgado, V. L. \& Sparks, T. C. The spinosyns: chemistry, biochemistry, mode of action, and resistance. in Comprehensive Molecular Insect Science, Vol. 6 (eds Gilbert, L. J., latrou, K. \& Gill, S. S.) 137-173 (Elsevier, Oxford, UK, 2005).

19 Yao, R. C., Mertz, F. P., Nakatsukasa, W. M. \& Boeck, L. D. A83543, a novel insecticide complex, produced by Saccharopolyspora spinosa sp. nov.-taxonomy and fermentation. Abstr. Second Int. Conf. Biotechnol. Microb. Prod., P-20 (Sarasota, FL 1990))

20 Boeck, L. D. et al. (DowElanco) Process for producing A83543 compounds. US patent no. 5,342,634 (8 November 1994).
21 Boeck, L. D. et al. (DowElanco) Insecticide and miticide A83543 compounds and their method of production by fermentation. US patent no. 5,496,931 (5 March 1996).

22 Baker, P. J. (DowElanco) Process for isolating A83543 and its components. US patent no. 5,227,295 (13 July 1993).

23 Thompson, G. D. et al. Spinosyns: an overview of new natural insect management systems. Proc. Beltwide Cotton Production Conference 1039-1043 San Antonio, TX (1995).

24 Kirst, H. A. et al. A83543A-D, unique fermentation-derived tetracyclic macrolides. Tetrahedron Lett. 32, 4839-4842 (1991).

25 Bertasso, M. et al. Ripromycin and other polycyclic macrolactams from Streptomyces sp. Tü 6239: faxonomy, fermentation, isolation and biological properties. J. Antibiot. 56, 364-371 (2003)

26 Seto, H. et al. Structural studies of capsimycin and biosynthetic studies of ikarugamycin. Chem. Abstr. 92, 211459u (1979).

27 Nakatsukasa, W. M. et al. The use of ${ }^{13} \mathrm{C}$-NMR spectroscopy in biosynthetic studies of the insecticide, A83543. Abstr. Second Int. Conf. Biotechnol. Microb. Prod., P-21 (Sarasota, FL 1990).

28 Evans, D. A. \& Black, W. C. Total synthesis of (+)-A83543A [(+)-lepicidin A]. J. Am. Chem. Soc. 115, 4497-4513 (1993).

29 Paquette, L. A., Collado, I. \& Purdie, M. Total synthesis of spinosyn A. 2. Degradation studies involving the pure factor and its complete reconstitution. J. Am. Chem. Soc. $120,2553-2562$ (1998).

30 Mergott, D. J., Frank, S. A. \& Roush, W. R. Total synthesis of (-)-spinosyn A. Proc. Natl Acad. Sci. USA 101, 11955-11959 (2004).

31 Winbush, S. M., Mergott, D. J. \& Roush, W. R. Total synthesis of (-)-spinosyn A: examination of structural features that govern the stereoselectivity of the key transannular Diels-alder reaction. J. Org. Chem. 73, 1818-1829 (2008).

32 Banwell, M. et al. Chemoenzymatic approaches to the decahydro-as-indacene cores associated with the spinosyn class of insecticide. J. Chem. Soc. Perkin Trans. I 2000, 3555-3558 (2000)

33 Tietze, L. F., Brasche, G., Stadler, C., Grube, A. \& Bohnke, N. Multiple palladiumcatalyzed reactions for the synthesis of analogues of the highly potent insecticide spinosyn A. Angew. Chem. Int. Ed. 45, 5015-5018 (2006).

34 Tietze, L. F., Brasche, G., Grube, A., Bohnke, N. \& Stadler, C. Synthesis of novel spinosyn A analogues by Pd-mediated transformations. Chem. Eur. J. 13, 8543-8563 (2007).

35 Graupner, P. R., Martynow, J. \& Anzeveno, P. B. Spinosyn G, proof of structure by semisynthesis. J. Org. Chem. 70, 2154-2160 (2005).

36 Sparks, T. C. et al. Chemistry and biology of the spinosyns: components of spinosad (Tracer), the first entry into DowElanco's Naturalyte class of insect control products. Proc. Beltwide Cotton Production Conference Vol. 2, 692-696 Nashville, TN 1996)).

37 Sparks, T. C. et al. Fermentation-derived insect control agents - the spinosyns. in Methods in Biotechnology, Vol. 5, Biopesticides: Use and Delivery (eds Hall, F. R. \& Menn, J. J.) 171-188 (Humana, Totowa, NJ, 1999).

38 DeAmicis, C. V., Dripps, J. E., Hatton, C. J. \& Karr, L. L. Physical and biological properties of the spinosyns: novel macrolide pest-control agents from fermentation. in Phytochemicals for Pest Control (eds Hedin, P. A., Hollingworth, R. M., Maser, E. P., Miyamoto, J. \& Thompson, G. D.) Am. Chem. Soc. Symp. Series 658 144-154 (American Chemical Society, Washington DC, 1997).

39 Hahn, D. R. et al. Butenyl-spinosyns, a natural example of genetic engineering of antibiotic biosynthetic genes. J. Indust. Microbiol. Biotechnol. 33, 94-104 (2006).

40 Lewer, P. et al. Discovery of the butenyl-spinosyn insecticides: novel macrolides from the new bacterial strain Saccharopolyspora pogona. Bioorg. Med. Chem. 17, 4185-4196 (2009).

41 Parekh, S., Vinci, V. A. \& Strobel, R. J. Improvement of microbial strains and fermentation processes. Appl. Microbiol. Biotechnol. 54, 287-301 (2000).

42 Huang, K., Xia, L., Zhang, Y., Ding, X. \& Zahn, J. A. Recent advances in the biochemistry of spinosyns. Appl. Microbiol. Biotechnol. 82, 13-23 (2009).

43 Strobel Jr. R. J., \& Nakatsukasa, W. M. Response surface methods for optimizing Saccharopolyspora spinosa, a novel macrolide producer. J. Indust. Microbiol. 11, 121-127 (1993).

44 Madduri, K. et al. Genes for the biosynthesis of spinosyns: applications for yield improvement in Saccharopolyspora spinosa. J. Indust. Microbiol. Biotechnol. 27, 399-402 (2001).

45 Broughten, M. C., Huber, M. L. B., Creemer, L. C., Kirst, H. A. \& Turner, J. R. Biosynthesis of the macrolide insecticidal compound $\mathrm{A} 83543$ by Saccharopolyspora spinosa. Abstr. Am. Soc. Microbiol. Annual Meeting, K58 (Dallas, TX 1991).

46 Waldron, C. et al. A cluster of genes for the biosynthesis of spinosyns, novel macrolide insect control agents produced by Saccharopolyspora spinosa. Antonie van Leeuwenhoek 78, 385-390 (2000).

47 Waldron, C. et al. Cloning and analysis of the spinosad biosynthetic gene cluster of Saccharopolyspora spinosa. Chem. Biol. 8, 487-499 (2001).

48 Martin, C. J. et al. Heterologous expression in Saccharopolyspora erythraea of a pentaketide synthase derived from the spinosyn polyketide synthase. Org. Biomol. Chem. 1, 4144-4147 (2003).

49 Kim, H. J., Pongdee, R., Wu, Q., Hong, L. \& Liu, H.- W. The biosynthesis of spinosyn in Saccharopolyspora spinosa: synthesis of the cross-bridging precursor and identification of the function of SpnJ. J. Am. Chem. Soc. 129, 14582-14584 (2007).

50 Sheehan, L. S. et al. Engineering of the spinosyn PKS: directing starter unit incorporation. J. Nat. Prod. 69, 1702-1710 (2006).

51 Gaisser, S. et al. Glycosylation engineering of spinosyn analogues containing an L-olivose moiety. Org. Biomol. Chem. 7, 1705-1708 (2009). 
52 Hong, L., Melancon, C. E. , III, Zhang, H. \& Liu, H.- W. In vitro characterization of the enzymes involved in TDP-D-forosamine biosynthesis in the spinosyn pathway of Saccharopolyspora spinosa. J. Am. Chem. Soc. 130, 4954-4967 (2008).

53 Huang, K., Zahn, J. \& Han, L. SpnH from Saccharopolyspora spinosa encodes a rhamnosyl 4'-0-methyltransferase for biosynthesis of the insecticidal macrolide, spinosyn A. J. Indust. Microbiol. Biotechnol. 35, 1669-1676 (2008).

54 Hong, L., Zhao, Z. \& Liu, H.- W. Characterization of SpnQ from the spinosyn biosynthetic pathway of Saccharopolyspora spinosa: mechanistic and evolutionary implications for $\mathrm{C}-3$ deoxygenation in deoxysugar biosynthesis. J. Am. Chem. Soc. 128, 14262-14263 (2006).

55 Chen, Y.- L., Chen, Y.- H., Lin, Y.- C., Tsai, K.- C. \& Chiu, H.- T. Functional characterization and substrate specificity of spinosyn rhamnosyltransferase by in vitro reconstitution of spinosyn biosynthetic enzymes. J. Biol. Chem. 284, 7352-7363 (2009).

56 Sparks, T. C. et al. Biological activity of the spinosyns, new fermentation derived insect control agents on tobacco budworm (Lepidoptera: Noctuidae) larvae. J. Econ. Entomol. 91, 1277-1283 (1998).

57 Kirst, H. A. et al. Evaluation and development of spinosyns to control ectoparasites on cattle and sheep. Curr. Topics Med. Chem. 2, 675-699 (2002).

58 Thompson, G. D., Dutton, R. \& Sparks, T. C. Spinosad - a case study: an example from a natural products discovery programme. Pest Manag Sci 56, 696-702 (2000).

59 Dow AgroSciences, http://www. dowagro.com/prod/index.htm.

60 Racke, R. D. A reduced risk insecticide for organic agriculture - spinosad case study. in Crop Protection Products for Organic Agriculture: Environmental, Health, and Efficacy Assessment (eds Felsot, A. S. \& Racke, K. D.) 92-108 (American Chemical Society, Washington DC, 2007).

61 Dagani, R. Green Winners. Chem. Eng. News 77, 30-32 (1999).

$62 \mathrm{http}: / /$ www.elanco.com/products.html.

63 White, W. H. et al. Therapeutic and persistent efficacy of spinosad applied as a pouron or a topical spray against natural infestations of chewing and sucking lice on cattle. Vet. Parasitol. 143, 329-336 (2007).

64 White, W. H. et al. Knockdown and mortality comparisons among spinosad-, imidacloprid-, and methomyl-containing baits against susceptible Musca domestica (Diptera: Muscidae) under laboratory conditions. J. Econ. Entomol. 100, 155-163 (2007)

65 Cetin, H. et al. Comparative efficacy of spinosad with conventional acaricides against hard and soft tick populations from Antalya, Turkey. Vet. Parasitol. 163, 101-104 (2009).

66 Davey, R. B., George, J. E. \& Snyder, D. E. Efficacy of a single whole-body spray treatment of spinosad against Boophilus microplus (Acari: Ixodidae) on cattle. Vet. Parasitol. 99, 41-52 (2001).

67 Davey, R. B., Miller, J. A., George, J. E. \& Snyder, D. E. Effect of repeated spinosad treatments on cattle against Boophilus annulatus under south Texas field conditions. Southwest Entomol 30, 245-255 (2005).

68 Coronado, A. \& Kowalski, A. Current status of the new world screwworm Cochliomyia hominivorax in Venezuela. Med. Vet. Entomol. 23(suppl 1), 106-110 (2009).

69 De Deken, R. et al. The macrocyclic lactone 'spinosad,' a promising insecticide for tsetse fly control. J. Med. Entomol. 41, 814-818 (2004).

70 Snyder, D. E. et al. Preliminary studies of the effectiveness of the novel pulicide, spinosad, for the treatment and control of fleas on dogs. Vet. Parasitol. 150, 345-351 (2007)

71 Robertson-Plouch, C. et al. Clinical field study of the safety and efficacy of spinosad chewable tablets for controlling fleas on dogs. Vet. Ther. 9, 26-36 (2008).

72 Franc, M. \& Bouhsira, E. Evaluation of speed and duration of efficacy of spinosad tablets for treatment and control of Ctenocephalides canis (Siphonaptera: Pulicidae) infestations in dogs. Parasite (Paris, France) 16, 125-128 (2009).

73 Snyder, D. E., Cruthers, L. R. \& Slone, R. L. Preliminary study on the acaricidal efficacy of spinosad administered orally to dogs infested with the brown dog tick, Rhipicephalus sanguineus (Latreille, 1806) (Acari: Ixodidae). Vet. Parasitol. 166, 131-135 (2009).

74 Mougabure Cueto, G., Zerba, E. N. \& Picollo, M. I. Permethrin-resistant head lice (Anoplura: Pediculidae) in Argentina are susceptible to spinosad. J. Med. Entomol. 43, 634-635 (2006).

75 http://www.parapro.com.

76 Crouse, G. D. \& Sparks, T. C. Naturally derived materials as products and leads for insect control: the spinosyns. Rev. Toxicol. 2, 133-146 (1998).

77 DeAmicis, C. V. et al. (Dow AgroSciences). Synthetic modifications of spinosyn compounds. US patent no. 6,001,981 (14 December 1999).

78 Crouse, G. D. et al. Chemistry and insecticidal activity of the spinosyns. in Pesticide Chemistry and Bioscience: The Food-Environment Challenge (eds Brooks, G. T. \& Roberts, T. R.) 155-166 (Royal Society of Chemistry, London, 1999).

79 Crouse, G. D. et al. Recent advances in the chemistry of spinosyns. Pest Manag. Sci. 57, 177-185 (2001).

80 Sparks, T. C., Crouse, G. D. \& Durst, G. Natural products as insecticides: the biology, biochemistry and quantitative structure-activity relationships of spinosyns and spinosoids. Pest Manag. Sci. 57, 896-905 (2001).

81 Kirst, H. A., Creemer, L. C., Broughton, M. C., Huber, M. L. B. \& Turner, J. R. Chemical and microbial modifications of spinosyn: exploring synergies between fermentation microbiology and organic chemistry. in Synthesis and Chemistry of Agrochemicals VI (eds Baker, D. R., Fenyes, J. G., Lahm, G. P., Selby, T. P. \& Stevenson, T. M.) 251-261 (American Chemical Society, Washington DC, 2002).

82 Anzeveno, P. B. \& Green, F. R. , III. Rhamnose replacement analogs of spinosyn A. in Synthesis and Chemistry of Agrochemicals VI (eds Baker, D. R., Fenyes, J. G.,
Lahm, G. P., Selby, T. P. \& Stevenson, T. M.) 262-276 (American Chemical Society, Washington DC, 2002)

83 Huang, K., Xia, L., Zhang, Y., Ding, X. \& Zahn, J. A. Recent advances in the biochemistry of spinosyns. Appl. Microbiol. Biotechnol. 82, 13-23 (2009).

84 Creemer, L. C., Kirst, H. A. \& Paschal, J. W. Conversion of spinosyn A and spinosyn D to their respective 9- and 17-pseudoaglycones and their aglycones. J. Antibiot. 51, 795-800 (1998).

85 Martynow, J. G. \& Kirst, H. A. Chemistry of A83543A derivatives. 1. Oxidations and reductions of A83543A aglycon. J. Org. Chem. 59, 1548-1560 (1994).

86 Creemer, L. C., Kirst, H. A., Paschal, J. W. \& Worden, T. V. Synthesis and insecticidal activity of spinosyn analogs functionally altered at the $2^{\prime}, 3^{\prime}$, and $4^{\prime}$-positions of the rhamnose moiety. J. Antibiot. 53, 171-178 (2000)

87 DeAmicis, C. V. et al. The stereochemical outcome of electrophilic addition reactions on the 5,6-double bond in the spinosyns. J. Org. Chem. 66, 8431-8435 (2001).

88 Daeuble, J., Sparks, T. C., Johnson, P. \& Graupner, P. R. Modification of the butenylspinosyns utilizing cross-metathesis. Bioorg. Med. Chem. 17, 4197-4205 (2009).

89 Sparks, T. C. et al. The application of artificial neural networks to the identification of new spinosoids with improved biological activity toward larvae of Heliothis virescens. Pest. Biochem. Physiol. 67, 187-197 (2000).

90 Sparks, T. C. et al. Neural network-based QSAR and insecticide discovery: spinetoram. J. Comput. Aided Mol. Des. 22, 393-401 (2008).

91 Dripps, J., Olson, B., Sparks, T. \& Crouse, G. Spinetoram: how artificial intelligence combined natural fermentation with synthetic chemistry to produce a new spinosyn insecticide. Plant Health Progress $(22$ August 2008) http://www.plantmanagementnetwork.org/pub/php/perspective/2008/spinetoram/.

92 Crouse, G. D., Dripps, J. E., Orr, N., Sparks, T. C. \& Waldron, C. DE-175 (spinetoram), a new semi-synthetic spinosyn in development. in Modern Crop Protection Compounds, Vol. 3 (eds Kramer, W. \& Schirmer, U.) 1013-1031 (Wiley - VCH, Weinheim, Germany, 2007).

93 Orr, N., Shaffner, A. J., Richey, K. \& Crouse, G. D. Novel mode of action of spinosad: receptor binding studies demonstrating lack of interaction with known insecticidal target sites. Pest. Biochem. Physiol. 95, 1-5 (2009).

94 Salgado, V. L. Studies on the mode of action of spinosad: insect symptoms and physiological correlates. Pest. Biochem. Physiol. 60, 91-102 (1998).

95 Salgado, V. L., Sheets, J. J., Watson, G. B. \& Schmidt, A. L. Studies on the mode of action of spinosad: the internal effective concentration and the concentration dependence of neural excitation. Pest. Biochem. Physiol. 60, 103-110 (1998).

96 Watson, G. B. Actions of insecticidal spinosyns on $\gamma$-aminobutyric acid responses from small-diameter cockroach neurons. Pest. Biochem. Physiol. 71, 20-28 (2001).

97 Millar, N. S. \& Denholm, I. Nicotinic acetylcholine receptors: targets for commercially important insecticides. Invert. Neurosci. 7, 53-66 (2007).

98 Perry, T., McKenzie, J. A. \& Batterham, P. A Da6 knockout strain of Drosophila melanogaster confers a high level of resistance to spinosad. Insect Biochem. Mol. Biol. 37, 184-188 (2007)

99 Orr, N. et al. Spinosad: from nature to green chemistry to novel mode of action. Abstr. 11th IUPAC Int. Cong. Pesticide Chem., S4-3 (Kobe, Japan, 6-11 August 2006).

100 Chouinard, S. W. et al. Insecticide mode of action: gaining insight through model organism genetics. Abstr. 11 th IUPAC Int. Cong. Pesticide Chem., S7-1 (Kobe, Japan, 6-11 August 2006)

101 Scott, J. G. Toxicity of spinosad to susceptible and resistant strains of house flies, Musca domestica. Pesticide Sci. 54, 131-133 (1998).

102 Scott, J. G., Alefantis, T. G., Kaufman, P. E. \& Rutz, D. A. Insecticide resistance in house flies from caged-layer poultry facilities. Pest Manag. Sci. 56, 147-153 (2000).

103 Zhao, J.- Z. et al. Monitoring and characterization of diamondback moth (Lepidoptera: Plutellidae) resistance to spinosad. J. Econ. Entomol. 95, 430-436 (2002).

104 Sayyed, A. H., Saeed, S., Noor-Ul-Ane, M. \& Crickmore, N. Genetic, biochemical, and physiological characterization of spinosad resistance in Plutella xylostella (Lepidoptera: Plutellidae). J. Econ. Entomol. 101, 1658-1666 (2008).

105 Mota-Sanchez, D., Wise, J. C., Poppen, R. V., Gut, L. J. \& Hollingworth, R. M. Resistance of codling moth, Cydia pomonella, (L.) (Lepidoptera: Tortricidae) larvae in Michigan to insecticides with different modes of action and the impact on field residual activity. Pest Manag. Sci. 64, 881-890 (2008).

106 Reyes, M. \& Sauphanor, B. Resistance monitoring in codling moth: a need for standardization. Pest Manag. Sci. 64, 945-953 (2008).

107 Osorio, A. et al. Monitoring of beet armyworm resistance to spinosad and methoxyfenozide in Mexico. Pest. Manag. Sci. 64, 1001-1007 (2008).

108 Ahmad, M. \& Iqbal Arif, M. Resistance of Pakistani field populations of spotted bollworm Earias vittella (Lepidoptera: Noctuidae) to pyrethroid, organophosphorous and new chemical insecticides. Pest Manag. Sci. 65, 433-439 (2009).

109 Sayyed, A. H., Ahmad, M. \& Saleem, M. A. Cross-resistance and genetics of resistance to indoxacarb in Spodoptera litura (Lepidoptera: Noctuidae). J. Econ. Entomol. 101, 472-479 (2008)

110 Magana, C., Hernandez-Crespo, P., Ortego, F. \& Castanera, P. Resistance to malathion in field populations of Ceratitis capitata. J. Econ. Entomol. 100, 1836-1843 (2007).

111 Lambkin, T. A. \& Rice, S. J. Baseline responses of Alphitobius diaperinus (Coleoptera: Tenebrionidae) to spinosad, and susceptibility of broiler populations in Eastern and Southern Australia. J. Econ. Entomol. 100, 1423-1427 (2007).

112 Bielza, P. et al. Resistance to spinosad in the western flower thrips, Frankliniella occidentalis (Pergande) in greenhouses of south-eastern Spain. Pest Manag. Sci. 63, 682-687 (2007).

113 Mota-Sanchez, D., Hollingworth, R. M., Grafius, E. J. \& Moyer, D. D. Resistance and cross-resistance to neonicotinoid insecticides and spinosad in the Colorado potato 
beetle, Leptinotarsa decemlineata (Say) (Coleoptera: Chrysomelidae). Pest Manag. Sci. 62, 30-37 (2006).

114 Dunley, J. E., Brunner, J. F., Doerr, M. D. \& Beers, E. H. Resistance and cross resistance in populations of the leafrollers, Choristoneura rosaceana and Pandemis pyrusana, in Washington apples. J. Insect Sci. 6, 1-7 (2006).

115 Nayak, M. K. \& Daglish, G. J. Combined treatments of spinosad and chlorpyrifosmethyl for management of resistant psocid pests (Psocoptera: Liposcelididae) of stored grain. Pest Manag. Sci. 63, 104-109 (2007).

116 Miles, M. \& Eelen, H. The effects of spinosad to beneficial insects and mites and its use in IPM. Commun. Agric. Appl. Biol. Sci. 71/2B, 275-284 (2006).

117 Eelen, H., Gobin, B. \& Miles, M. Field studies to determine the effects of spinosad on the predatory bugs Anthocoris nemoralis and A. nemorum. Commun. Agric. Appl. Biol. Sci. 71/2B, 429-432 (2006).

118 Miles, M. The effects of spinosad on beneficial insects and mites used in integrated pest management systems in greenhouses. IOBC/wprs Bull. (Pesticides Benef. Organisms) 29, 53-59 (2006).

119 Mayes, M. A., Thompson, G. D., Husband, B. \& Miles, M. M. Spinosad toxicity to pollinators and associated risk. Rev. Environ. Contam. Toxicol. 179, 37-71 (2003).

120 Miles, M. \& Dutton, R. Testing the effects of spinosad to predatory mites in laboratory, extended laboratory, semi-field and field studies. IOBC/wprs Bull. (Pesticides Benef. Organisms) 26, 9-20 (2003).

121 Miles, M. The effects of spinosad, a naturally derived insect control agent to the honeybee. Bull. Insectol. 56, 119-124 (2003).

122 Williams, T., Valle, J. \& Vinuela, E. Is the naturally derived insecticide spinosad compatible with insect natural enemies? Biocont. Sci. Tech. 13, 459-475 (2003).

123 Cisneros, J. et al. Toxic effects of spinosad on predatory insects. Biol. Control 23, 156-163 (2002).

124 Chapman, A. V. et al. Integrating chemical and biological control of European corn borer in bell pepper. J. Econ. Entomol. 102, 287-295 (2009).
125 Galvan, T. L., Koch, R. L. \& Hutchison, W. D. Toxicity of commonly used insecticides in sweet corn and soybean to multicolored Asian lady beetle (Coleoptera: Coccinellidae). J. Econ. Entomol. 98, 780-789 (2005).

126 Thompson, G. D. \& Sparks, T. C. Spinosad: a green natural product for insect control. in Advancing Sustainability Through Green Chemistry and Engineering, ACS Symp. Series 823 (eds Lankey, R. L. \& Anastas, P. T.) 61-73 (American Chemical Society, Washington DC, 2002).

127 Cleveland, C. B. et al. Environmental fate of spinosad. 1. Dissipation and degradation in aqueous systems. J. Agric. Food Chem. 50, 3244-3256 (2002).

128 West, S. D. Determination of the naturally derived insect control agent spinosad and its metabolites in soil, sediment, and water by HPLC with UV detection. J. Agric. Food Chem. 49, 3107-3113 (1997).

129 Hale, K. A. \& Portwood, D. E. The aerobic soil degradation of spinosad - a novel natural insect control agent. J. Environ. Sci. Health B31, 477-484 (1996).

130 Thompson, D. G., Harris, B. J., Lanteigne, L. J., Buscarini, T. M. \& Chartrand, D. T. Fate of spinosad in litter and soils of a mixed conifer stand in the Acadian forest region of New Brunswick. J. Agric. Food Chem. 50, 790-795 (2002).

131 Thompson, D. G., Harris, B. J., Buscarini, T. M. \& Chartrand, D. T. Fate of spinosad in litter and soils of a white spruce plantation in central Ontario. Pest. Manag. Sci. 58, 397-404 (2002).

132 Rothwell, J. T. et al. Residues of spinosad in the tissues of sheep after aerosol treatment of blowfly myiasis. Austral. J. Chem. 83, 154-156 (2005).

133 Baxter, S. W. et al. Mis-spliced transcripts of nicotinic acetylcholine receptor $\alpha 6$ are associated with field evolved spinosad resistance in Plutella xylostella (L.). PLoS Genet. 6, e1000802 (2010)

134 Roe, R. M. et al. Mechanism of resistance to spinosyn in the tobacco budworm, Heliothis virescens. Pest Biochem. Physiol. 96, 8-13 (2010).

135 Blagburn, B. L. et al. Effects of orally administered spinosad (Comfortis) in dogs on adult and immature stages of the cat flea (Ctenocephalides felis). Vet. Parasitol. (in press) (2009); doi:10.1016/j.vetpar.2009.11.023. 